\title{
Net Zero Energy Building Design in Tropical Climatic Conditions of Mumbai, India
}

\author{
Saunak Shukla ${ }^{1}$, Jeremy Lytle ${ }^{2}$, Kevin Ye $^{1}$, Wey Leong ${ }^{1}$, Alan Fung ${ }^{1}$ \\ ${ }^{1}$ Department of Mechanical Engineering, Ryerson University, Toronto, Canada \\ ${ }^{2}$ Department of Building Science, Ryerson University, Toronto, Canada
}

\begin{abstract}
Approximately $40 \%$ of the world's population currently reside in tropical geographical zones, defined as the region of the planet spanning between latitudes of $23^{\circ} \mathrm{N}$ and $23^{\circ} \mathrm{S}$. The tropical region is generally projected to be most adversely and rapidly affected by mechanisms of climate change. As a result, resilience in infrastructure and buildings is of paramount importance to the region. The present case study documents the design of a 17,500 $\mathrm{ft}^{2}\left(1,625 \mathrm{~m}^{2}\right)$ net zero energy building for a document storage and archive center in Mumbai, India. Net zero energy constitutes that the building's energy demands can be balanced with locally available and/or building installed Renewable Energy Sources (RES), on an annual basis.

A highlight of the design challenge in this climate is the high demand for cooling and dehumidification, with the archival zones of the building requiring constant air conditioning to maintain its artifacts within a specific set point of $65^{\circ} \mathrm{F}\left(18^{\circ} \mathrm{C}\right)$ and $40 \% \mathrm{RH}$. Decisions such as building orientation, building envelope, shading, and mechanical system selection are informed by comprehensive climate analysis. The prescriptive requirements set by 2018 International Green Construction Code is used as a reference design upon which a variety of further energy conservation measures (ECMs) are employed to achieve the net zero target. Considerations include building envelope optimization, LED lighting, solar hot water, airside energy/enthalpy recovery and other mechanical system upgrades. Climatic implications of ground source heat pump (GSHP) technology in the area are considered to investigate feasibility. Ultimately an iterative design process is conducted whereby each design iteration is evaluated against the reference case with regards to annual energy performance and life cycle cost over a 50-year operating horizon.

On-site generation is supplied by a rooftop solar photovoltaic (PV) array. This system benefits from the roof area of $2,075 \mathrm{~m}^{2}$, which is $27 \%$ larger than the building footprint. Solar resource in the proposed location is observed to exhibit limited seasonal fluctuation, with a monthly standard deviation of $19 \%$ of the mean production. Given this opportunistic contrast to the Canadian climate, which exhibits deviations in the order of $>40 \%$, the feasibility of on-site energy storage for resiliency considerations is also explored at a high level.
\end{abstract}

Word count: 360 